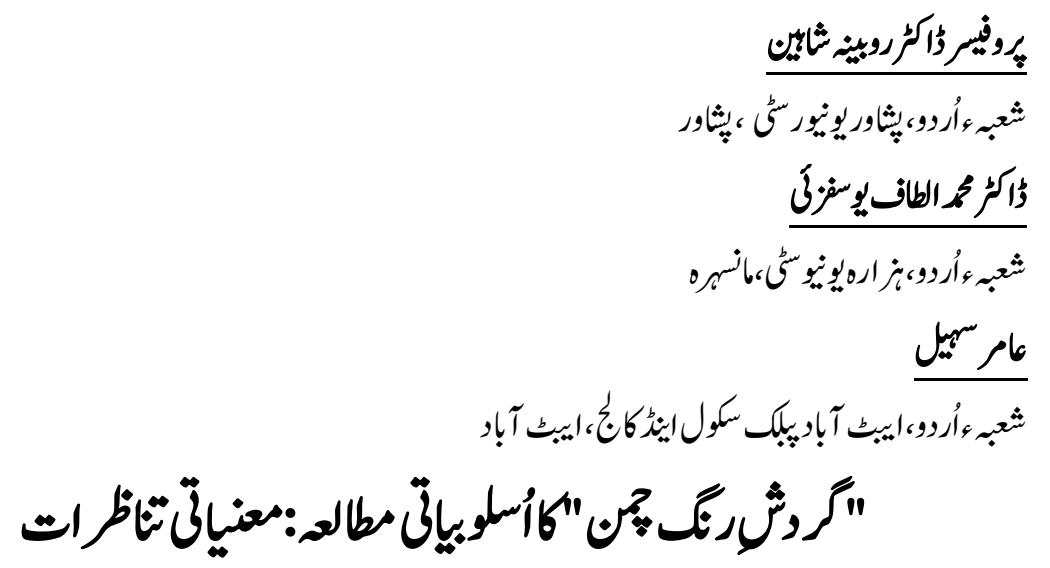

Prof. Dr. Rubina Shaheen

Department of Urdu, Peshawar University, Peshawar.

Dr. Muhammad Altaf Yousafzai

Department of Urdu, Hazara University, Mansehra.

\title{
Amir Sohail
}

Department of Urdu, Abbotabad Public School and College, Abotabad.

\section{A Stylistic Study of "Circulation of Color Reds": Semantic Perspectives}

Stylistics is one of the main branches of applied linguistics. It deals with the creative prose and poetry.it has four core areas like phonology, morphology, syntax and semantics. Sometimes we also discuss pragmatics as a fifth angle of the same discipline. In the present article I discussed the basic concepts of semantics especially with the reference of foregrounding, the use of English phraseology in Urdu text, enumeration and slang words. As my article is based on theoretical and the practical applications of some stylistics devices so I selected the the famous Urdu novel of Qutratul Ain Haider and pin pointed the major examples from the text. Semantics carries many major and minor literary devices which elaborate the text and the process of meaning in it.

Key Words: Stylistics, Branches, Applied Linguistics, Create, Prose, Poetry, Phonology, Morphology, Syntax, Semantics, Discipline. 


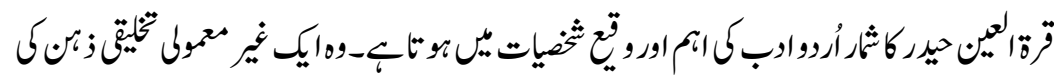

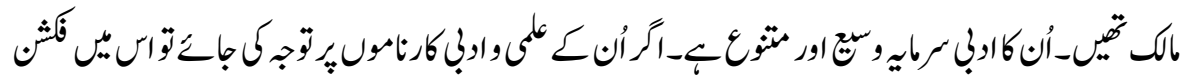

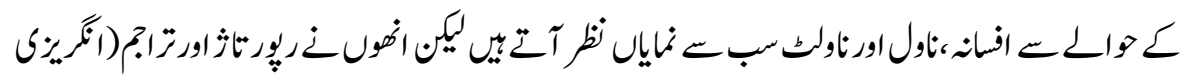

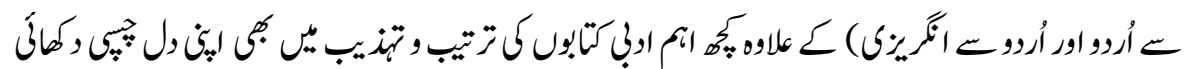

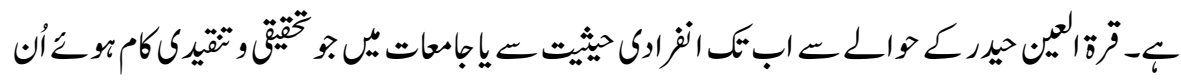

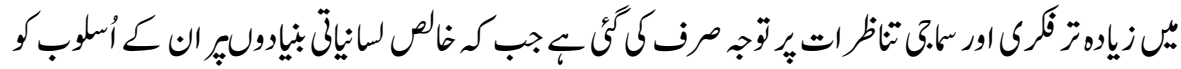

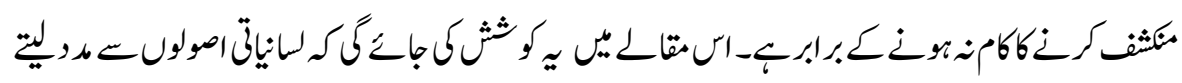

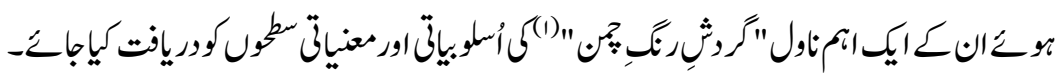

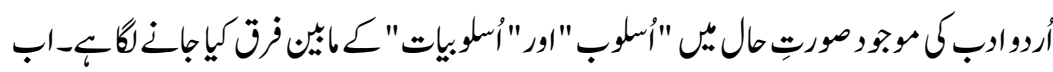

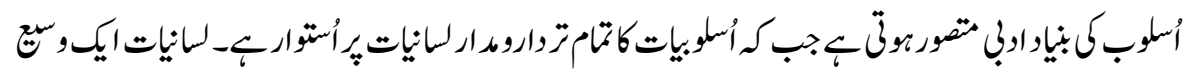

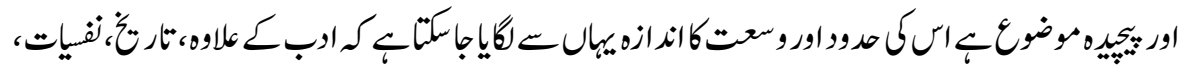

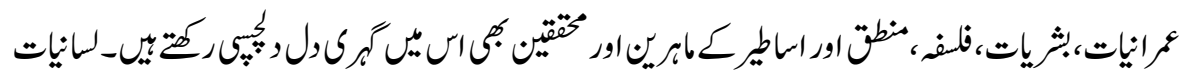

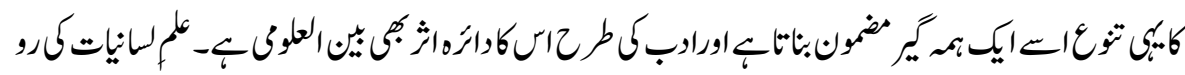

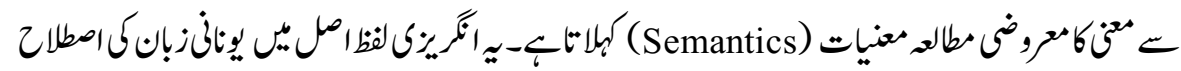
"Semantikos"

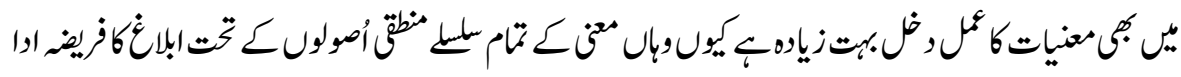

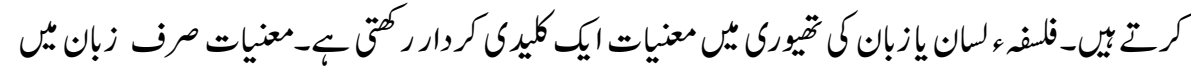

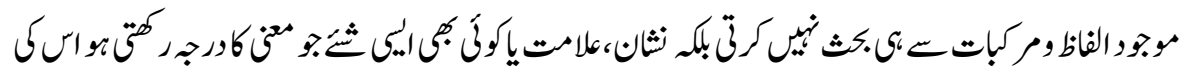

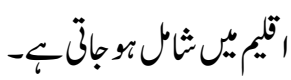

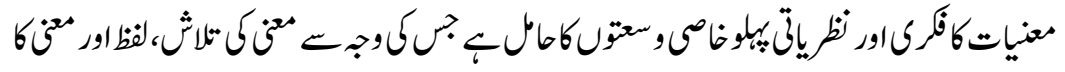

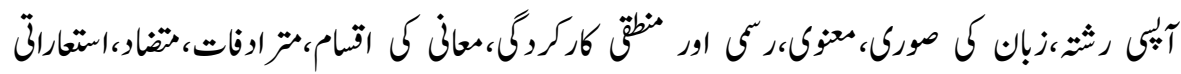

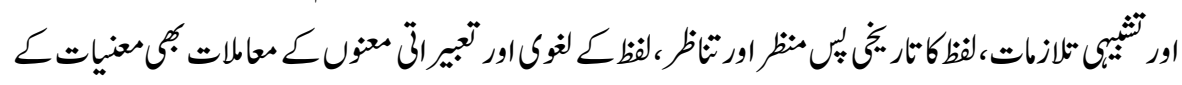

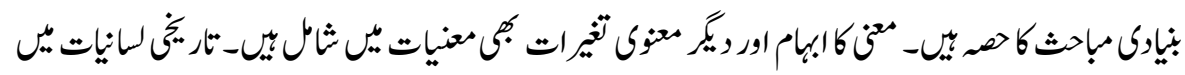




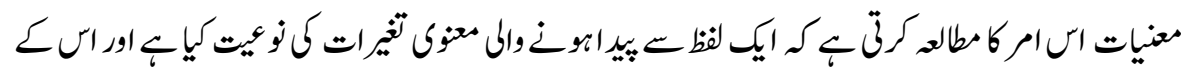

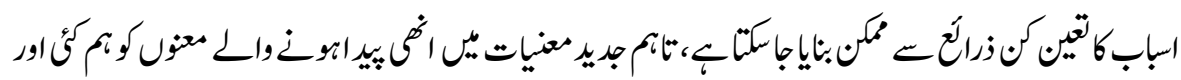

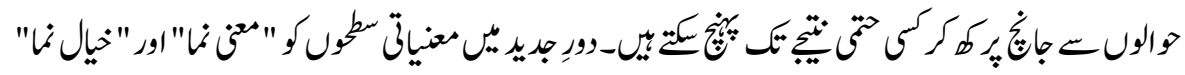

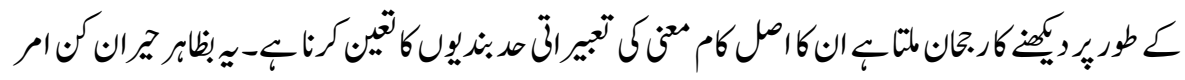

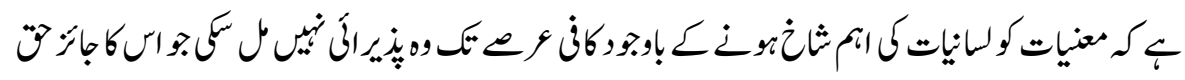

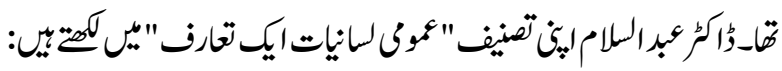

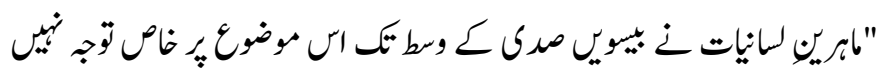

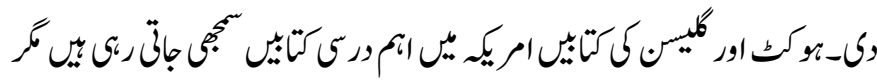

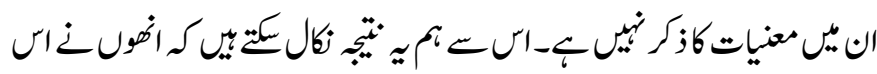

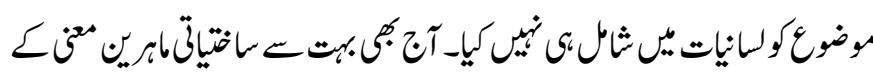

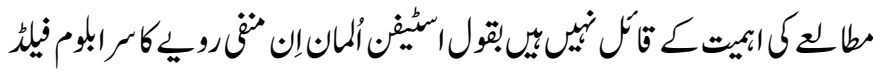

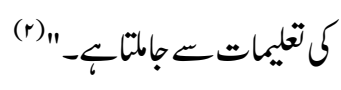

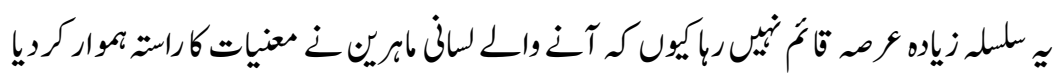

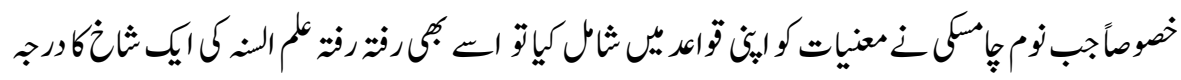

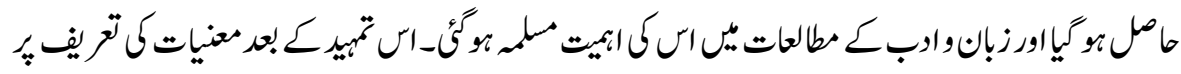

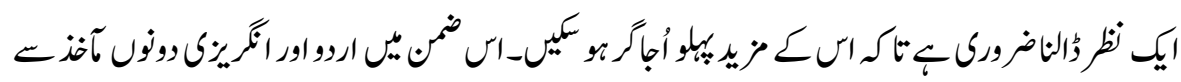

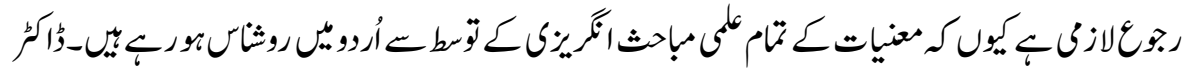

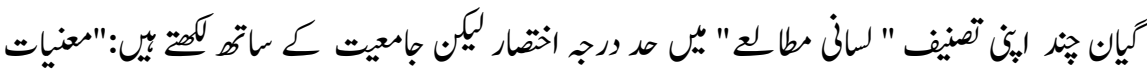
(semantics)

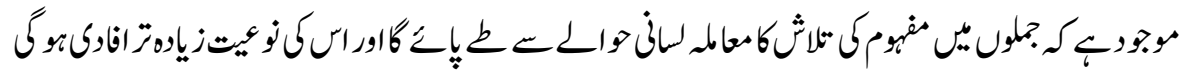

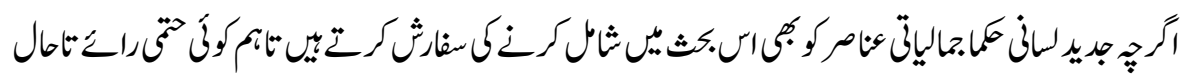

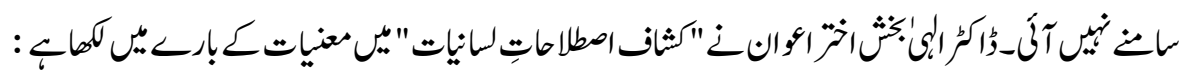




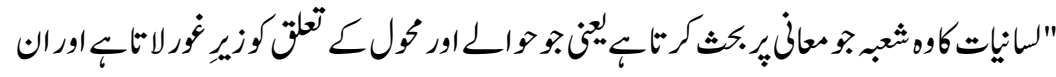

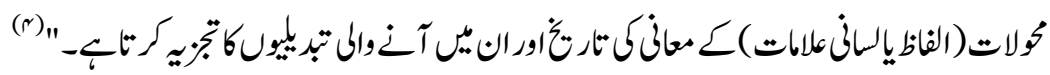

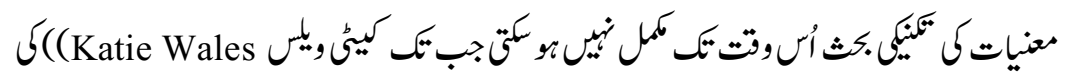

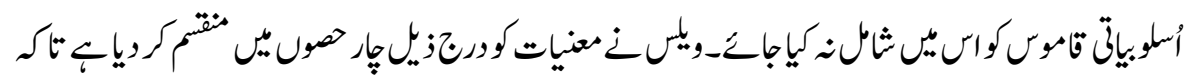

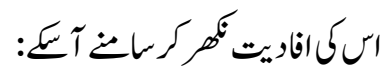

((Lexical Semantics

((Sentence Semantics$$
\text { مجاكمنمنيات }
$$

((Narrative Semantics

((Literary Semantics ${ }^{(5)}$

$$
\text { لنوكمنيات }
$$$$
\text { بيانيم منيات }
$$$$
\text { اربمنمنيات }
$$

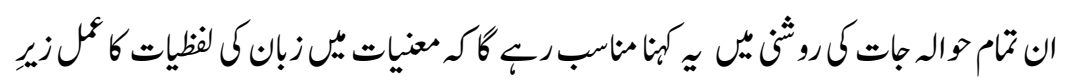

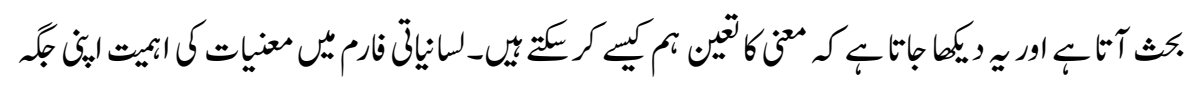

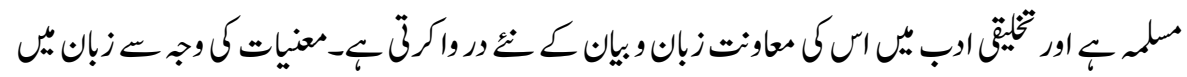

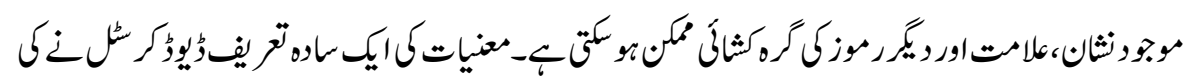

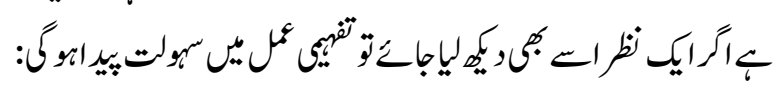

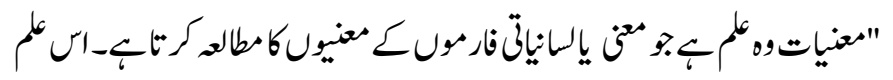

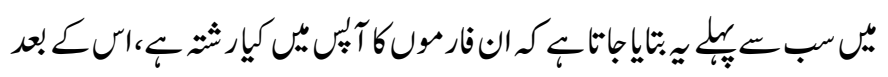

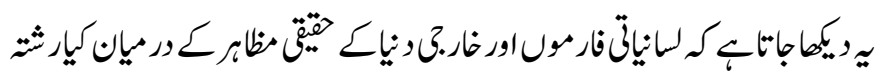

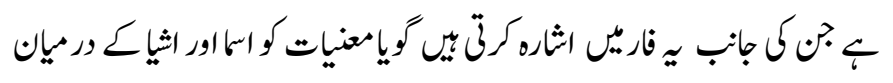

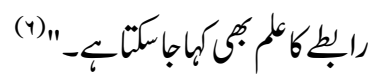

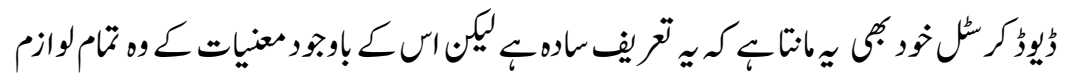

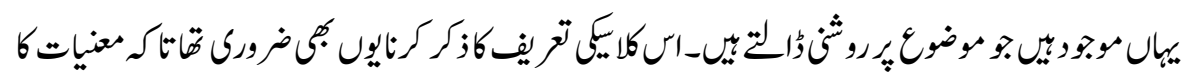

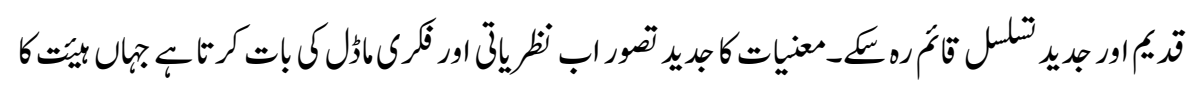

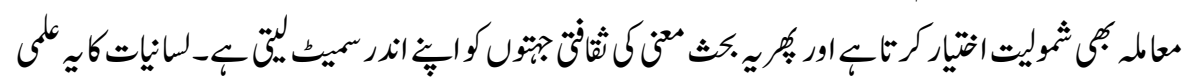




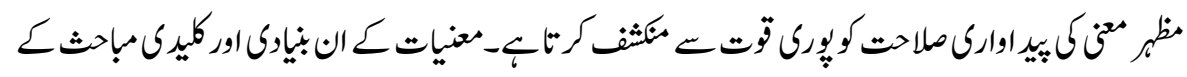

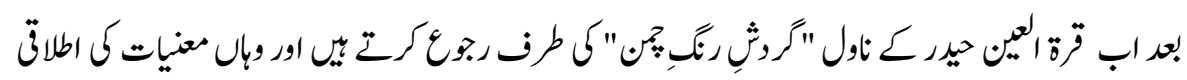

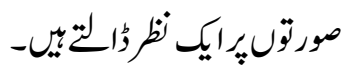

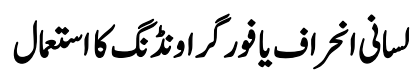

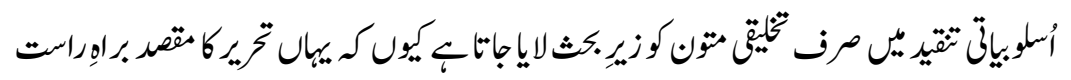

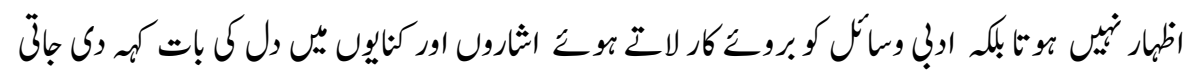

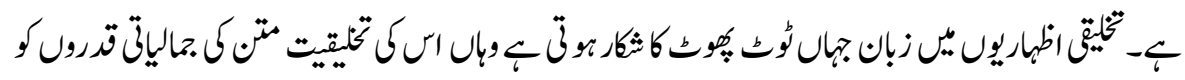

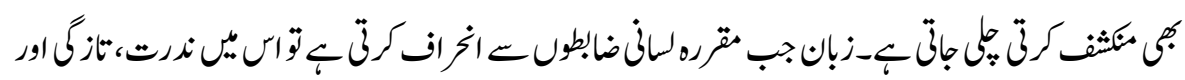

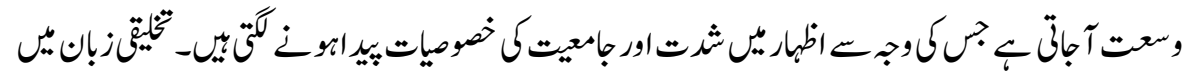

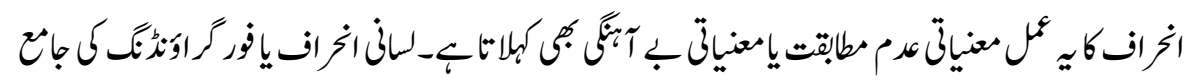

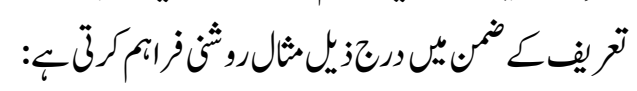

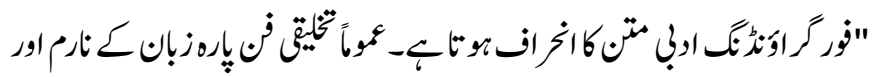

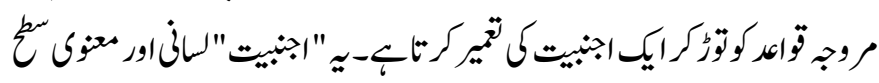

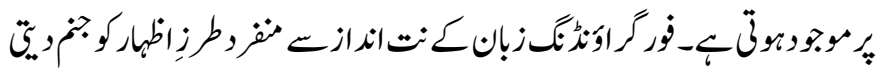

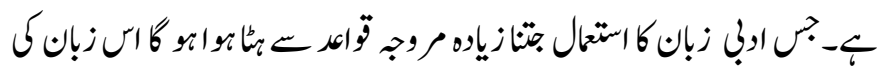

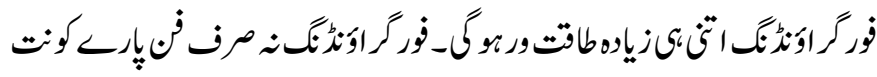

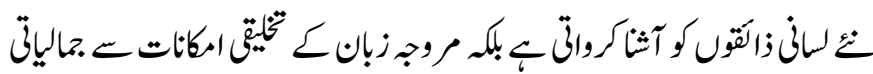

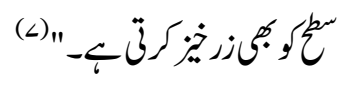

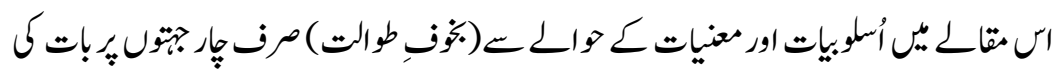

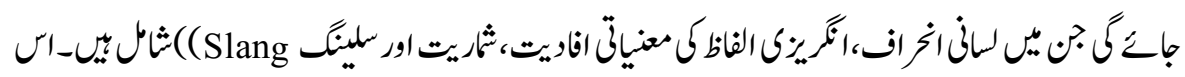

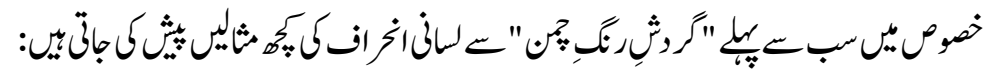

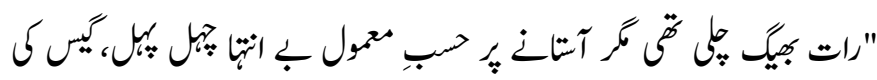

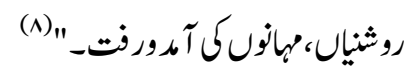




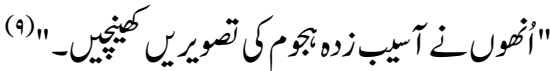

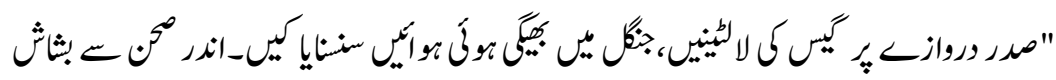

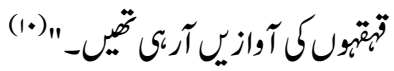

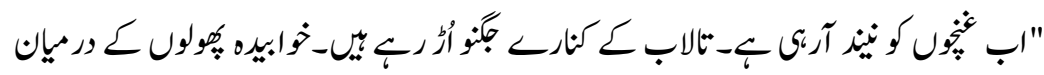

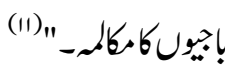

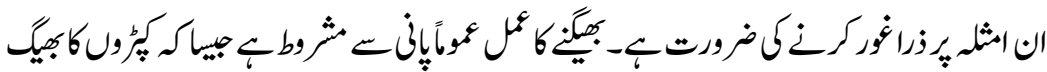

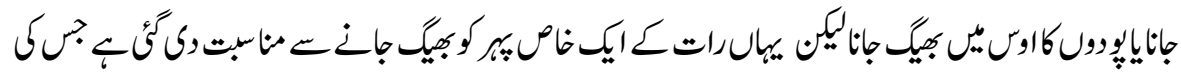

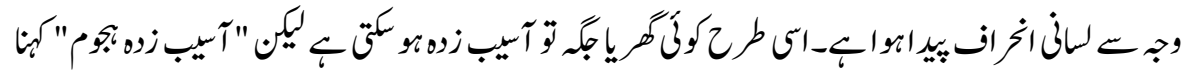

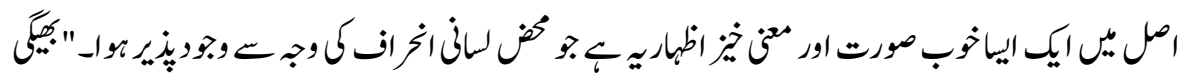

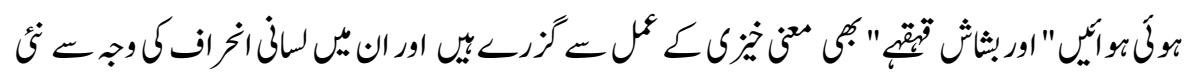

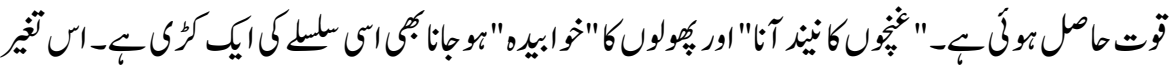

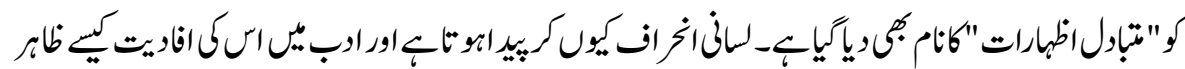

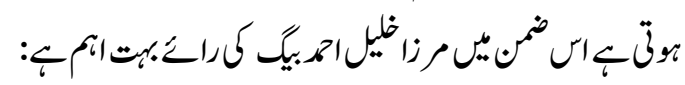

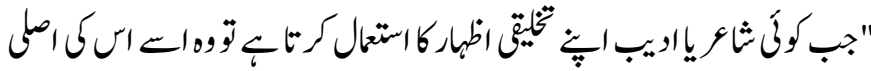

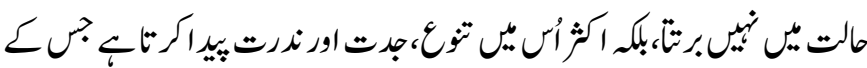

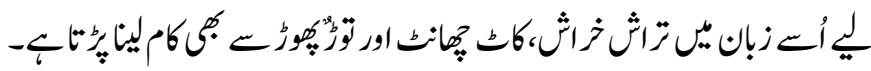

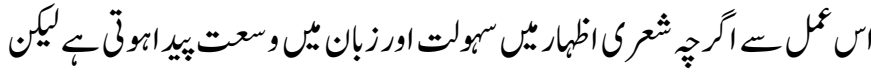

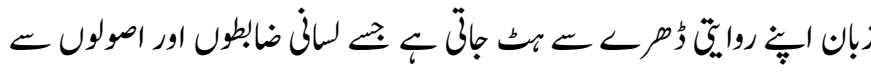

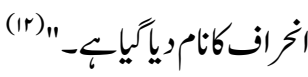

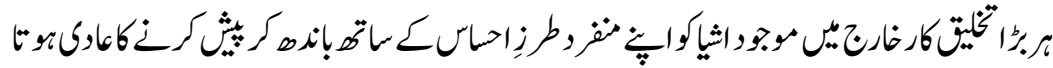

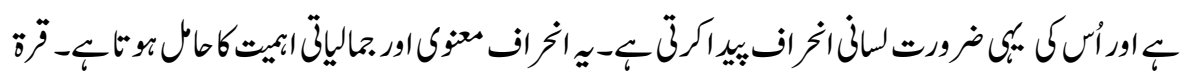

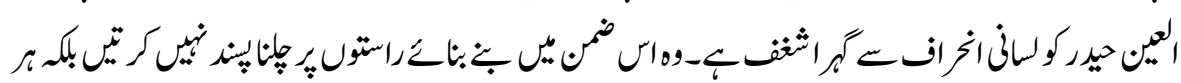

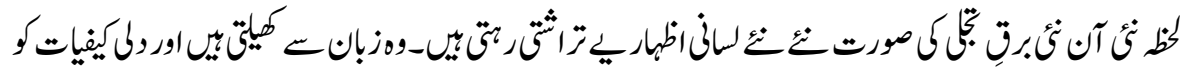




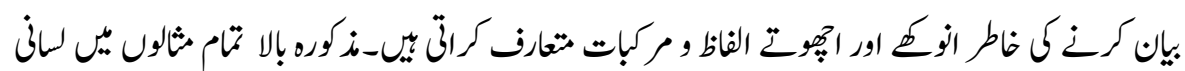

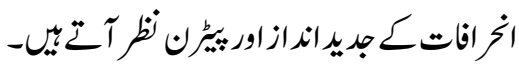
انتزيزكزبان ك الفاظوزخاكيب

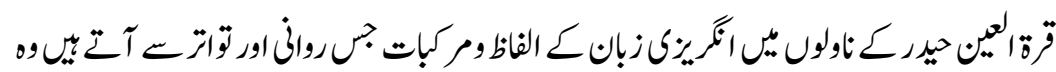

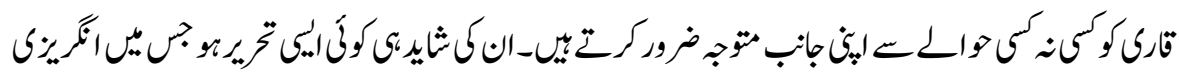

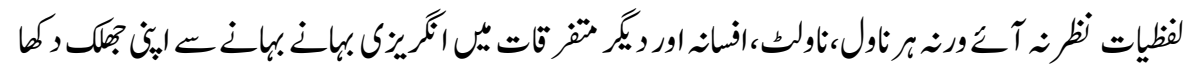

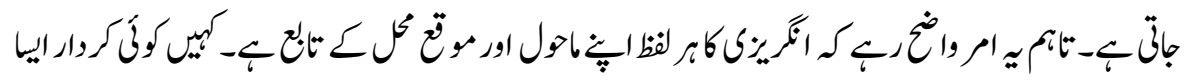

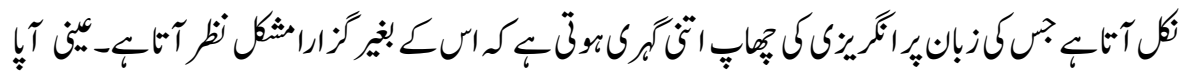

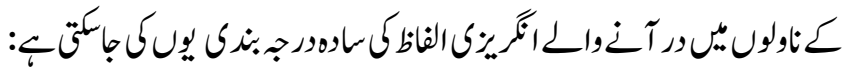

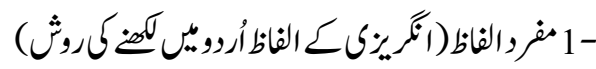

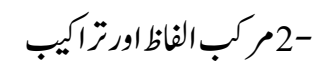

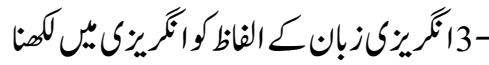
-

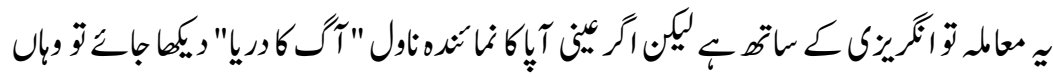

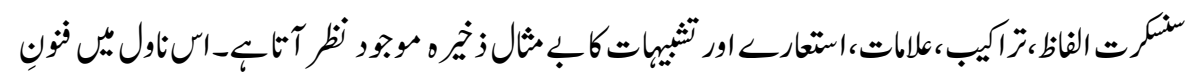

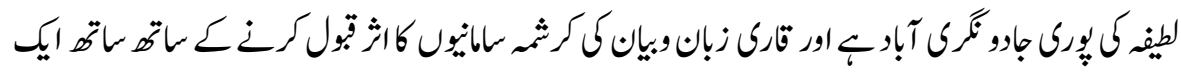

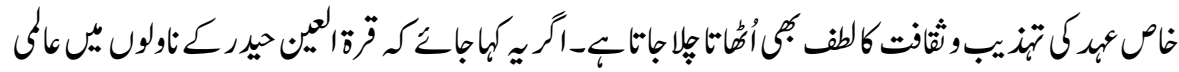

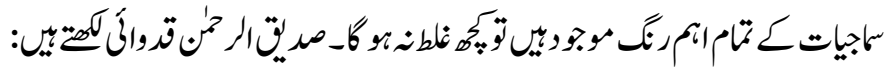

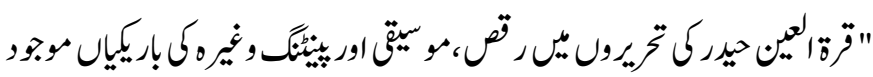

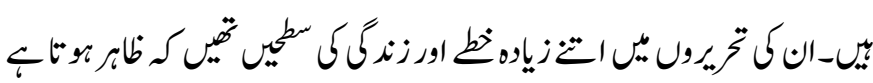

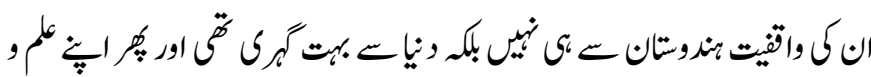

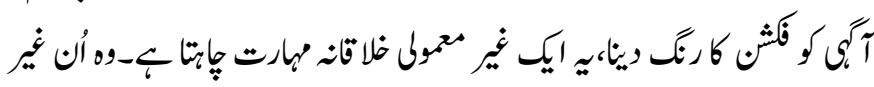




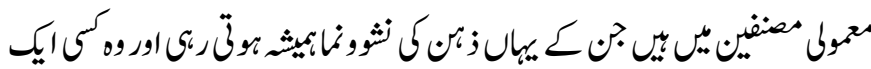

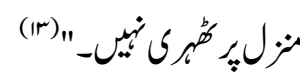

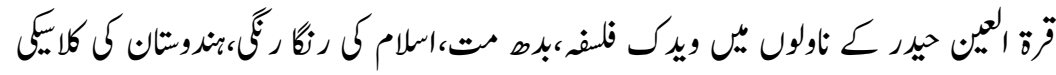

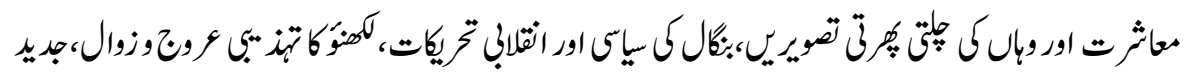

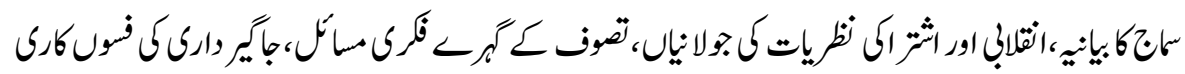

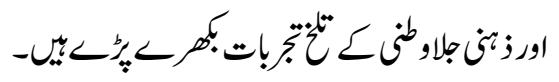

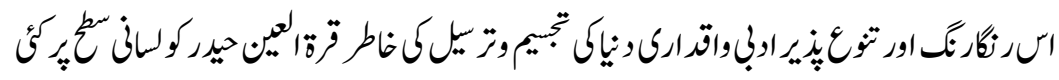

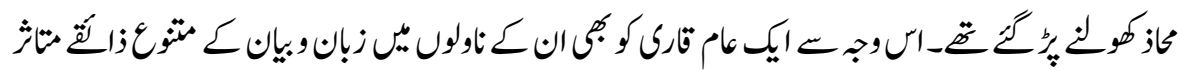

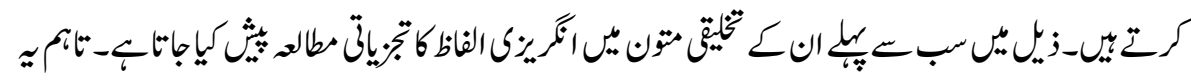

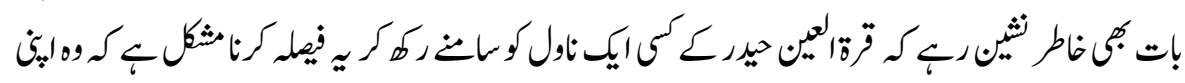

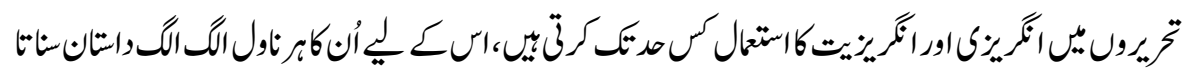

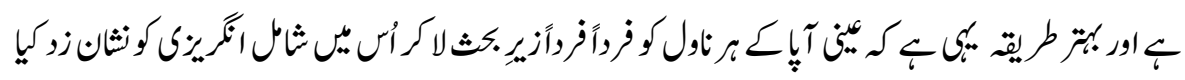

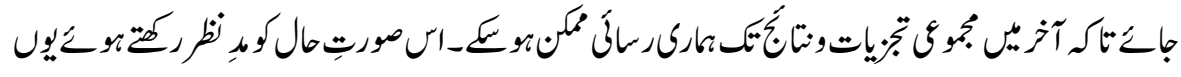

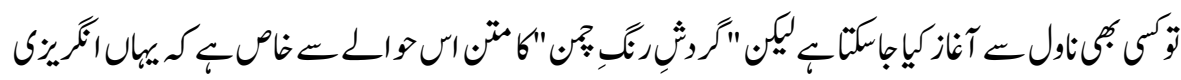

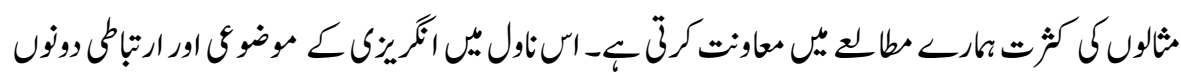

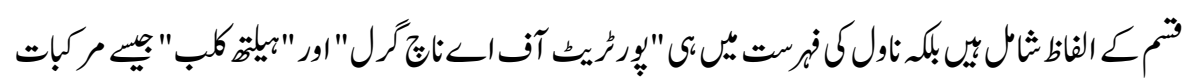

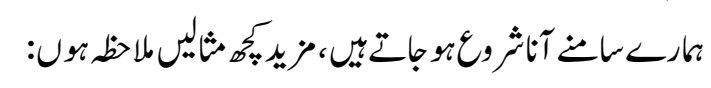

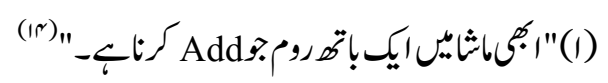

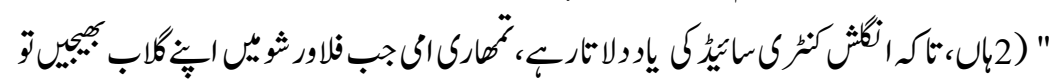

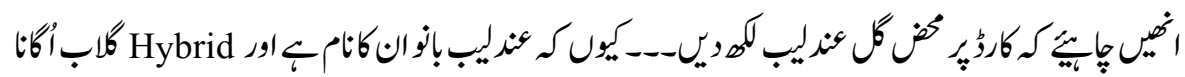

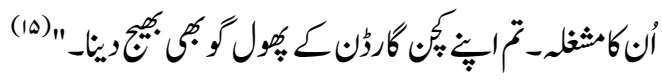




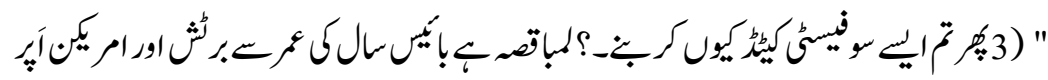

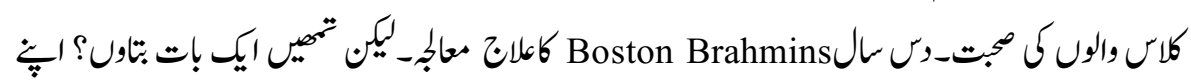

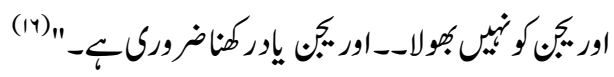

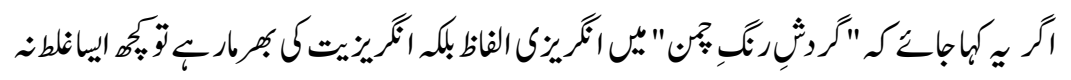

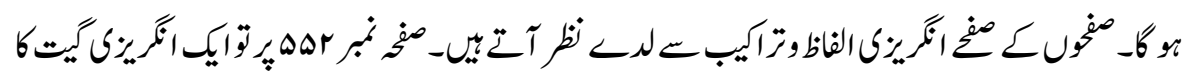

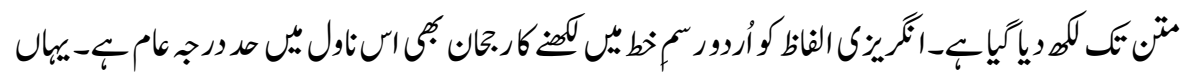

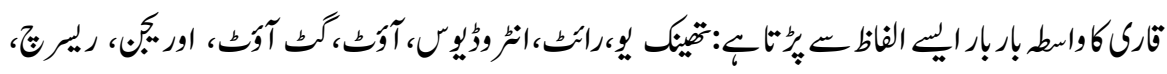

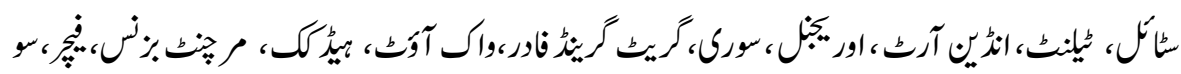

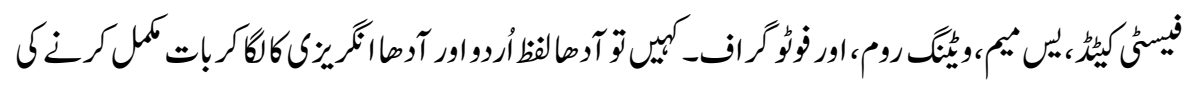

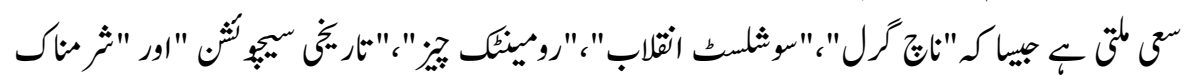

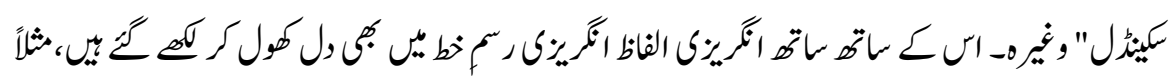
الئlioption,Absurd,Silly Goose,Hope,Wog,Figure of Tragedy,Dominate.

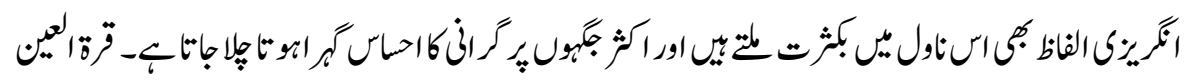

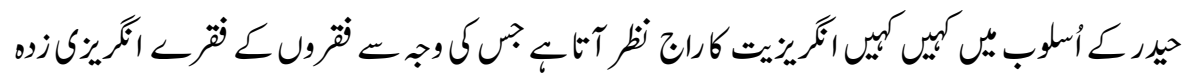

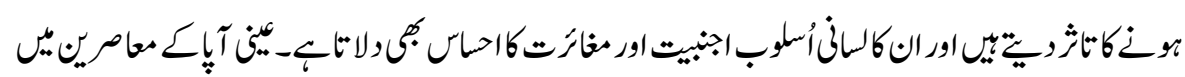

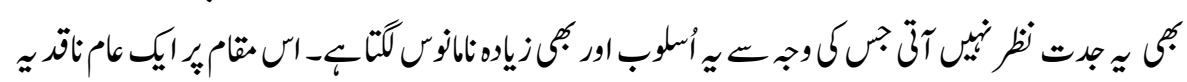

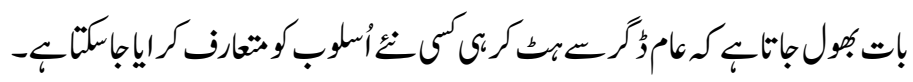

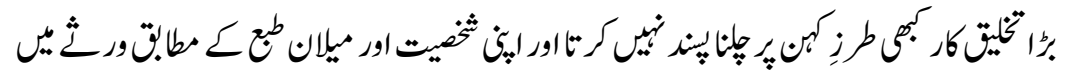

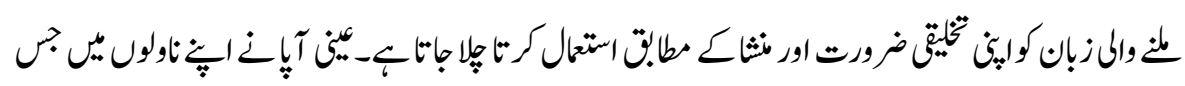

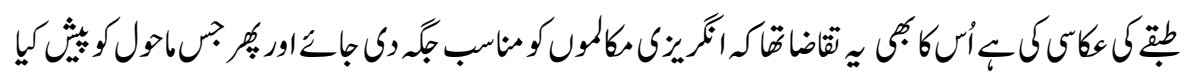

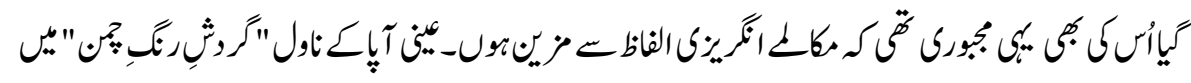

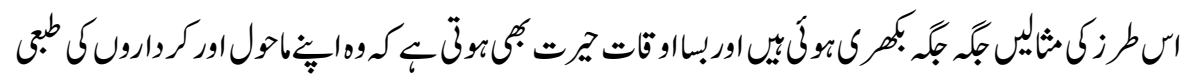

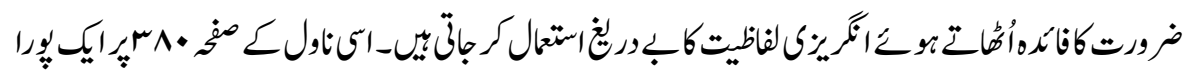




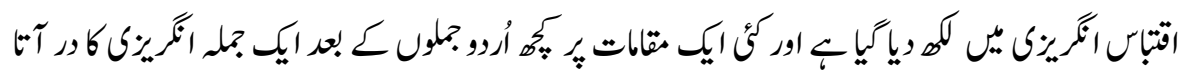

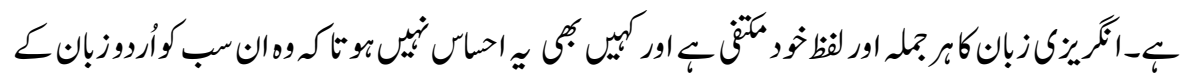

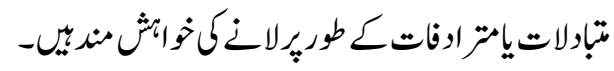

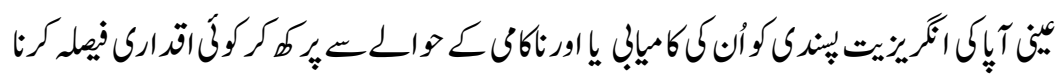

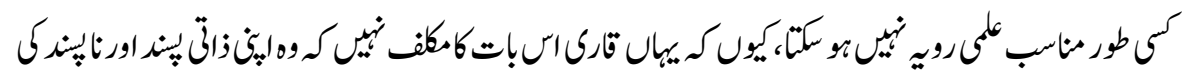

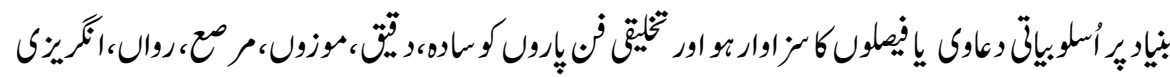

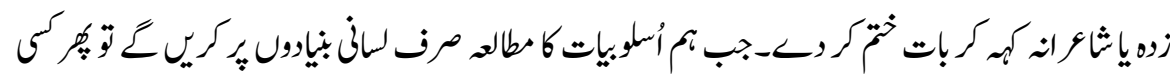

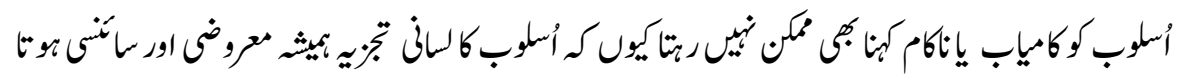

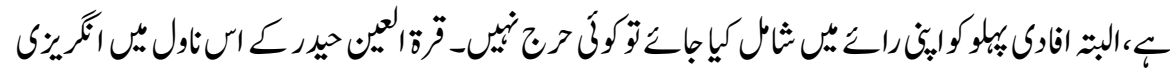

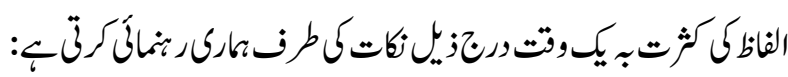

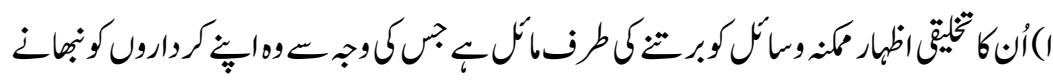

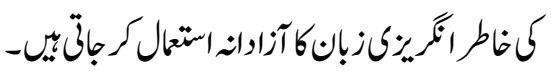

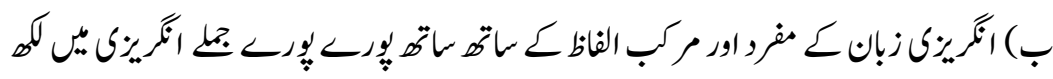

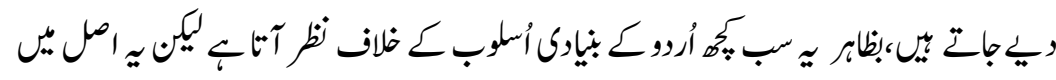

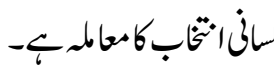

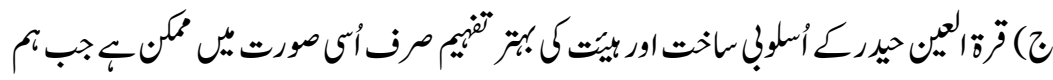

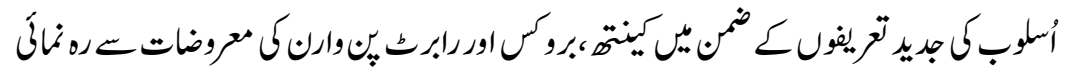

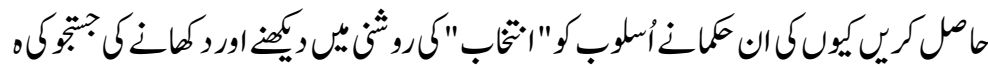

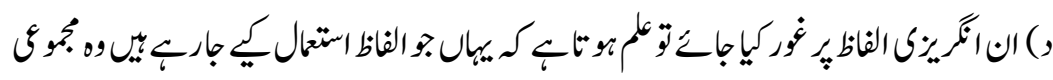

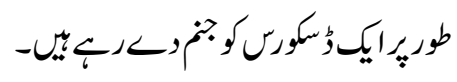

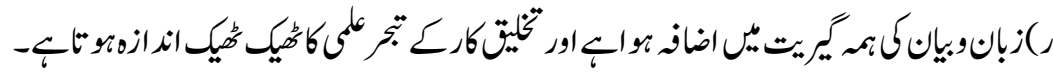

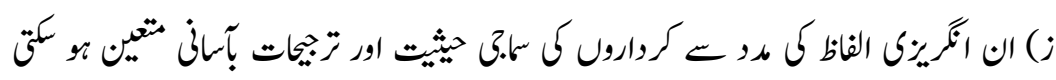

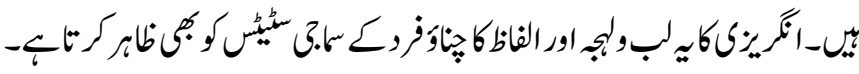




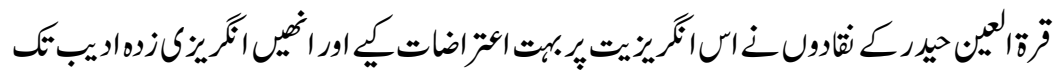

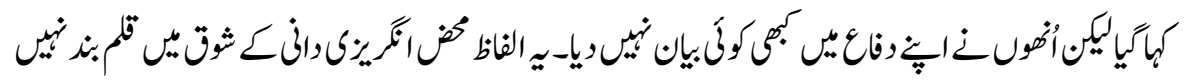

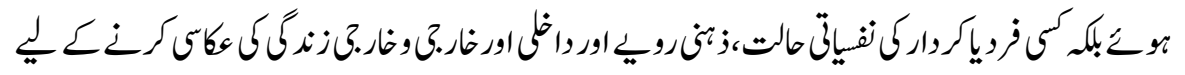

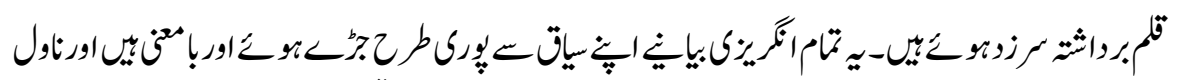

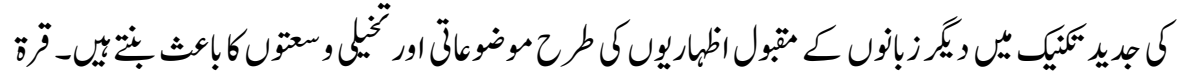

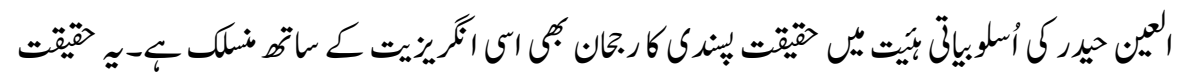

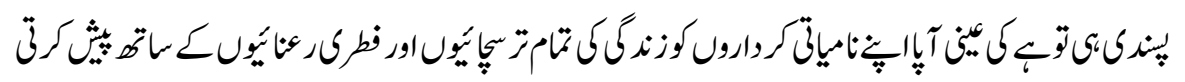

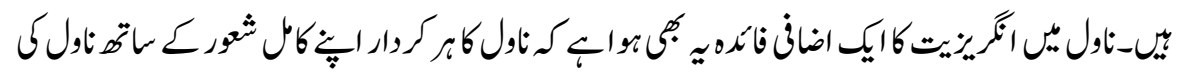

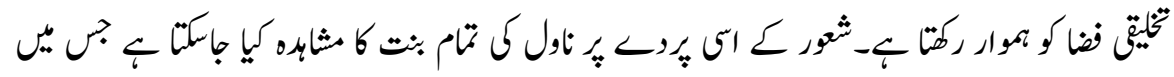

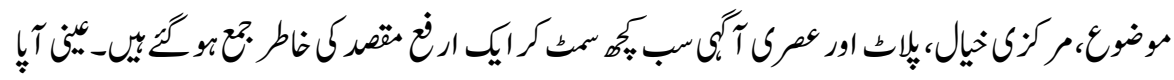

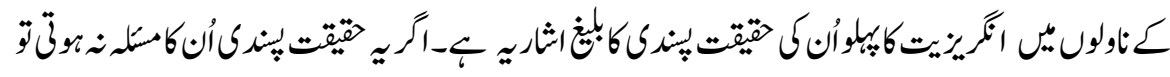

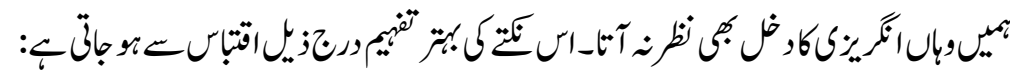

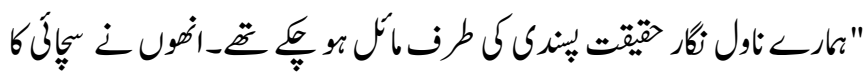

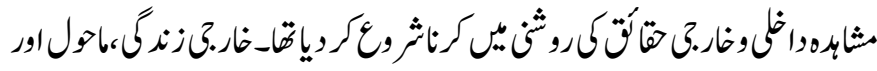

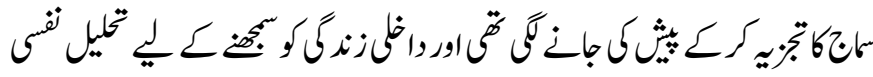

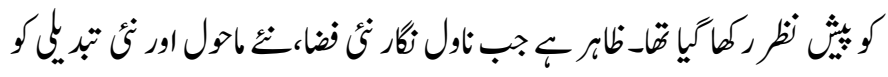

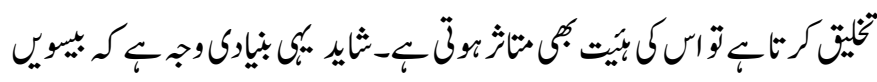

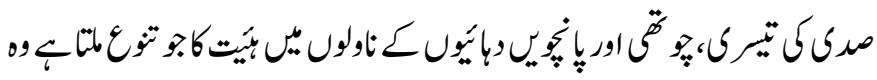

$$
\text { (1) "ن }
$$

\section{سلينّـنبانكاراتتعال}

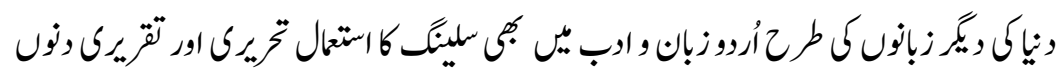

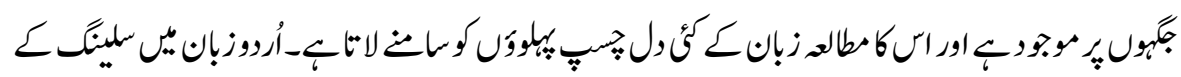

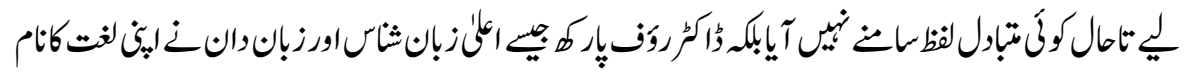




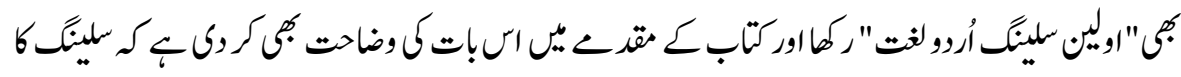

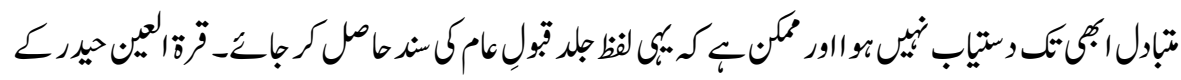

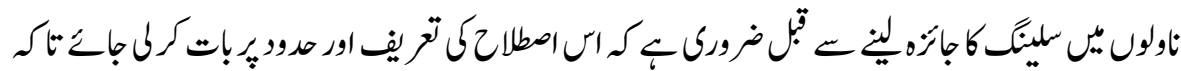

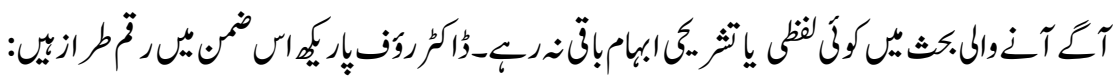

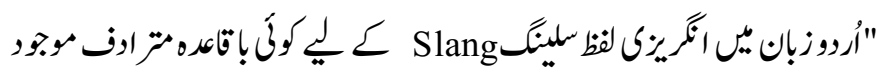

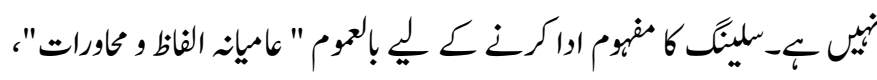

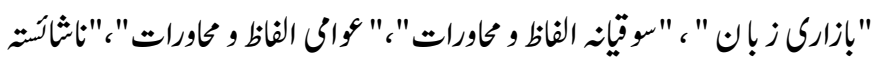

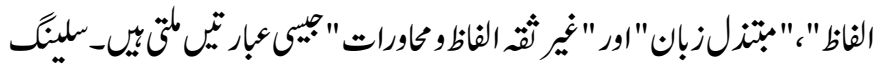

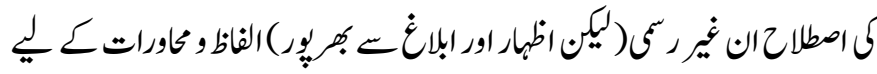

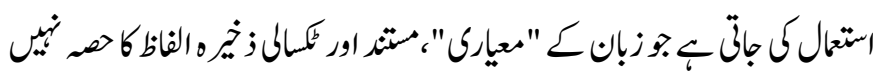

$$
\text { (1) "(1) }
$$

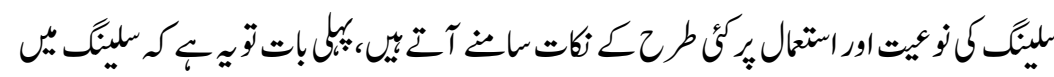

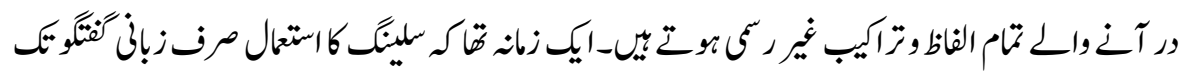

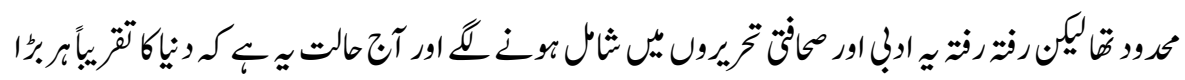

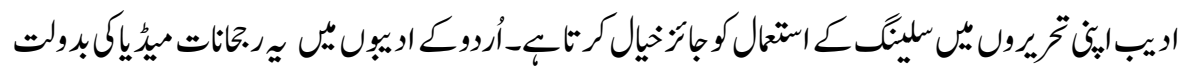

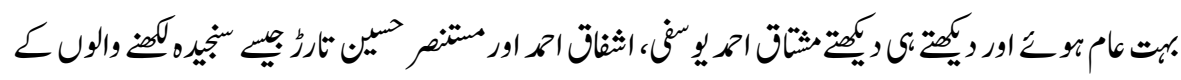

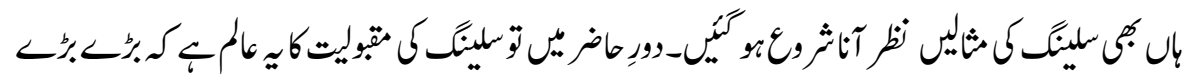

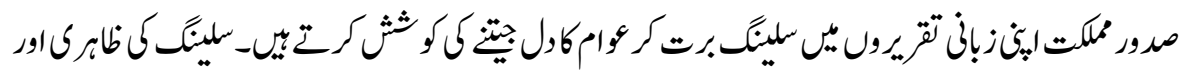

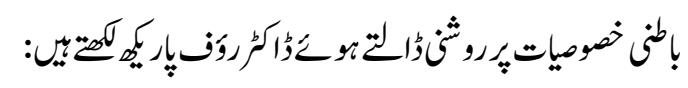

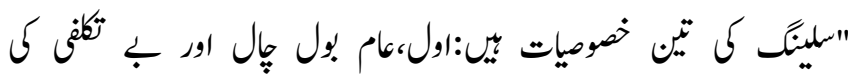

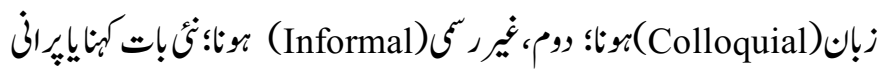

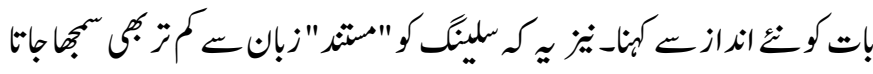

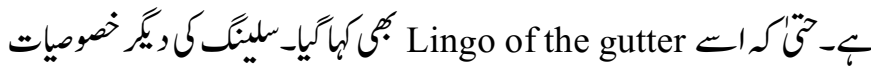




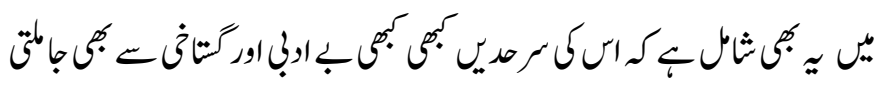

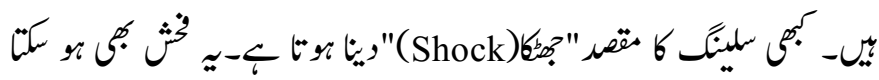

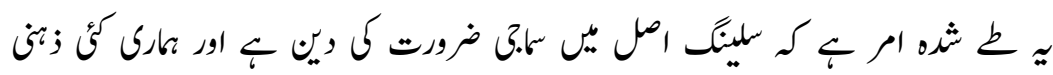

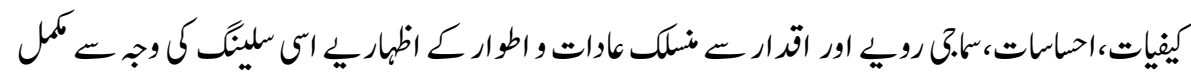

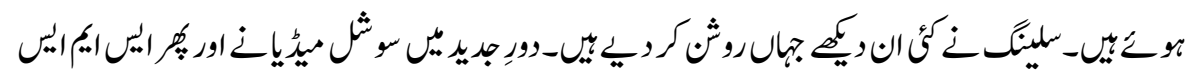

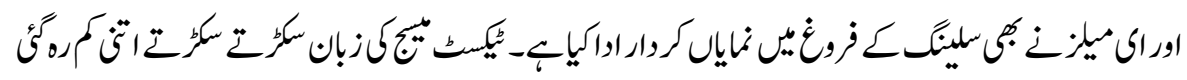

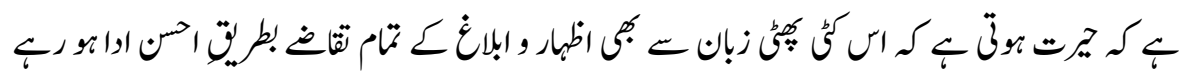

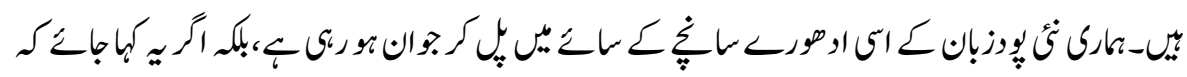

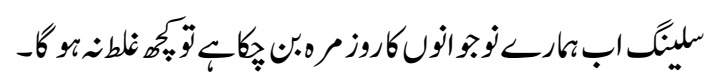

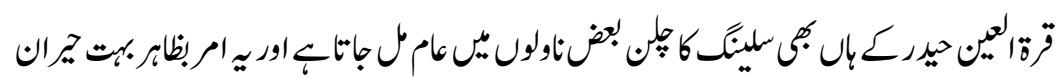

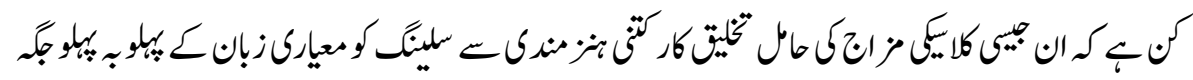

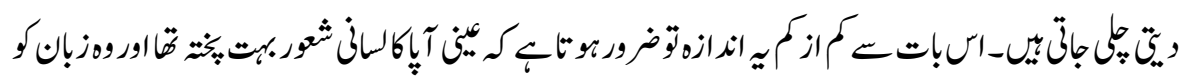

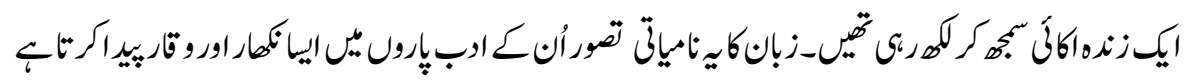

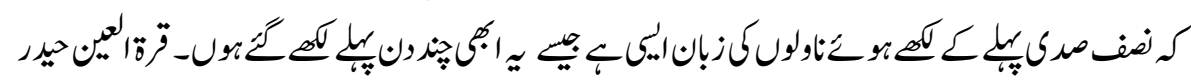

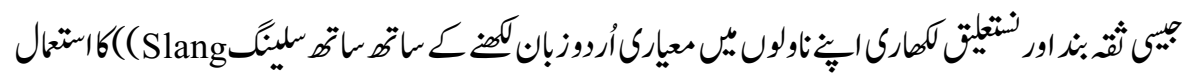

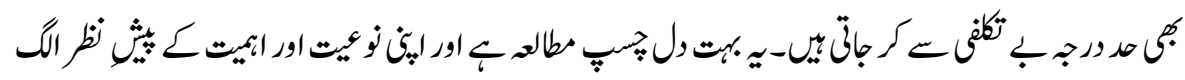

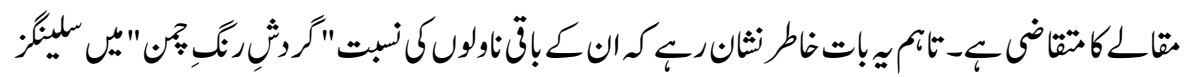

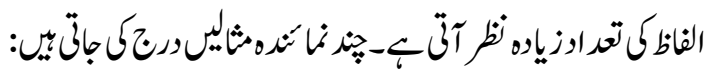

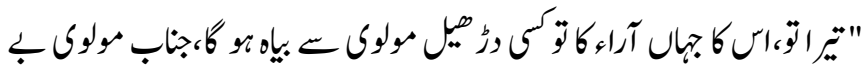

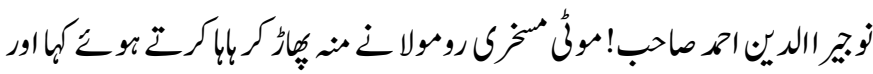

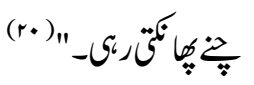

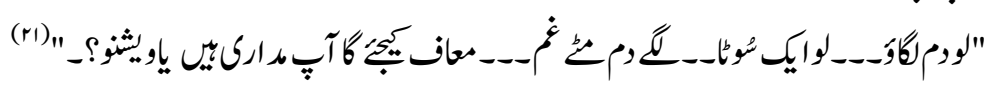




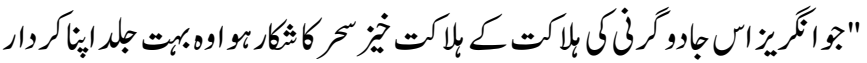

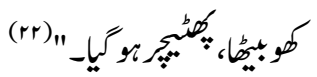

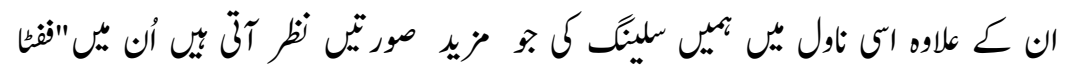

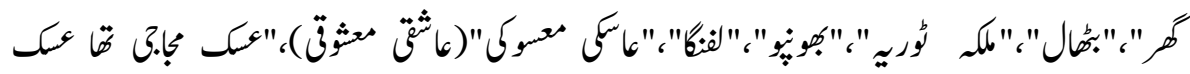

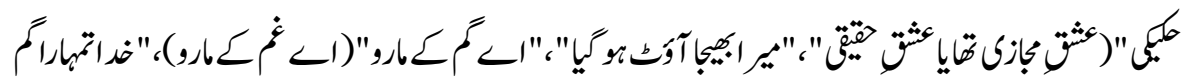

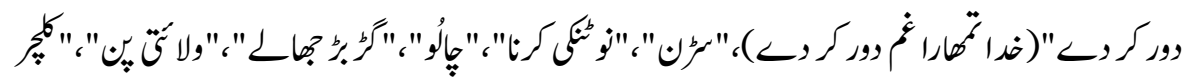

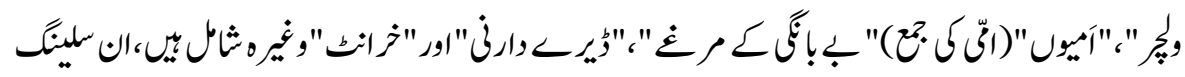

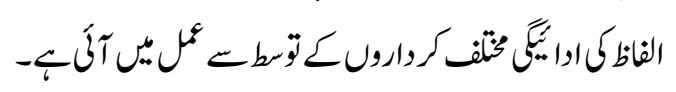

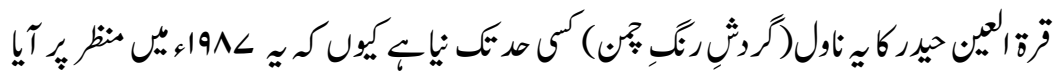

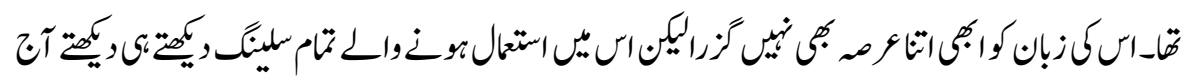

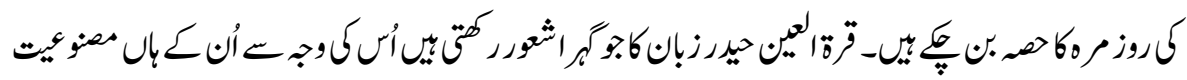

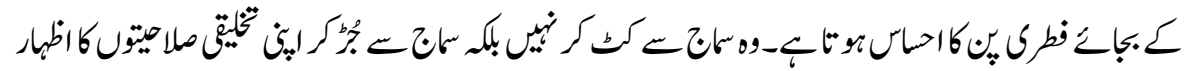

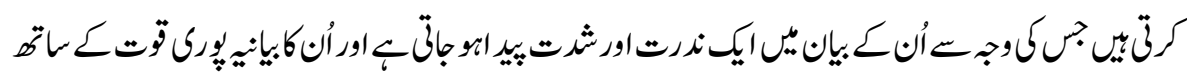

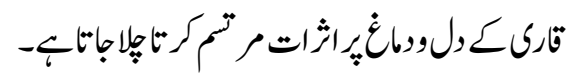

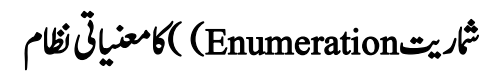

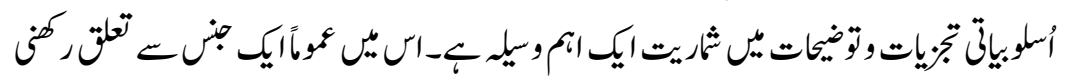

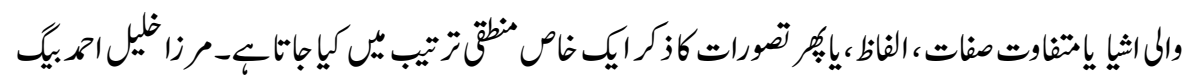

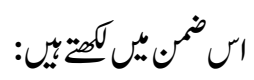

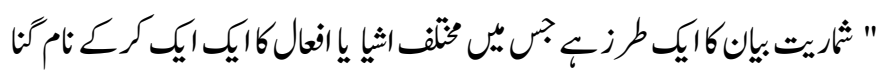

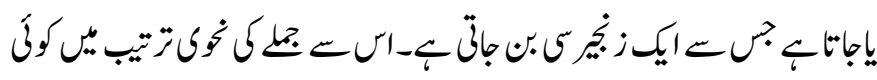

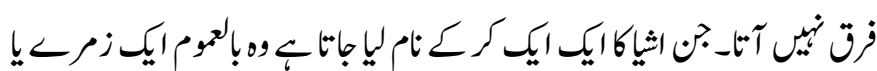

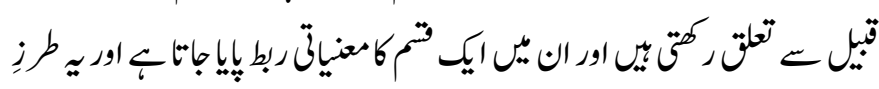

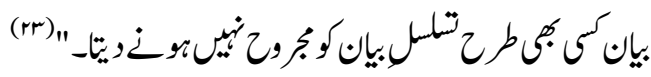




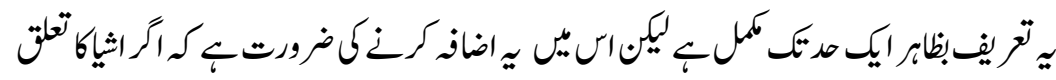

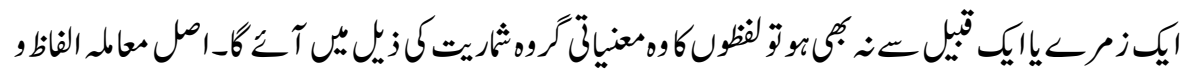

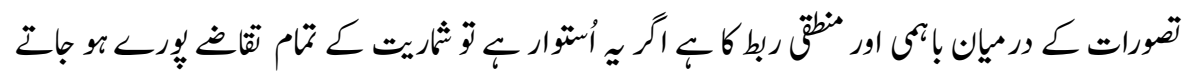

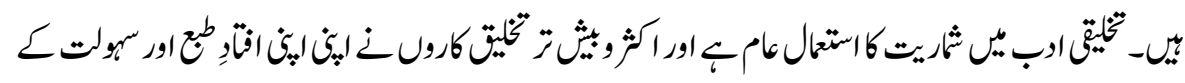

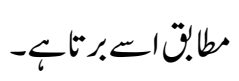

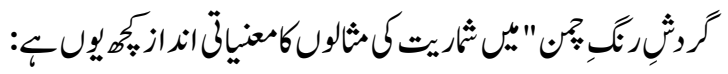

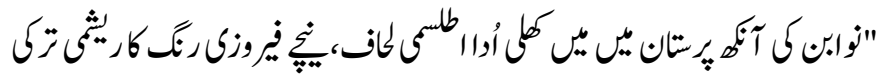

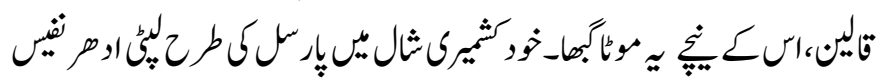

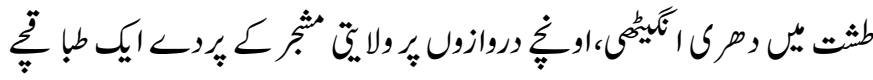

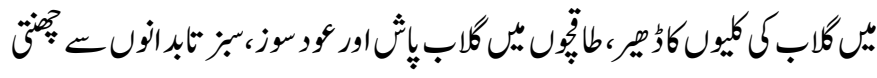

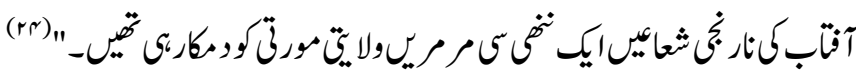

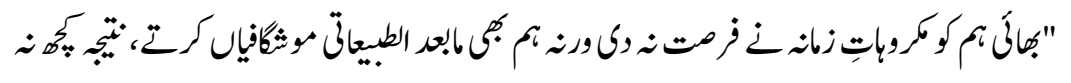

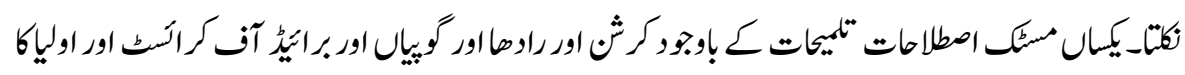

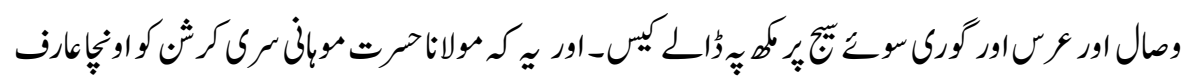

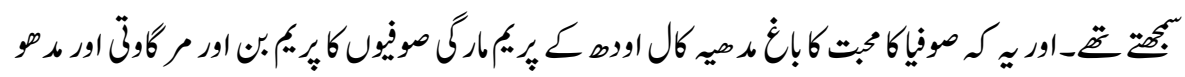

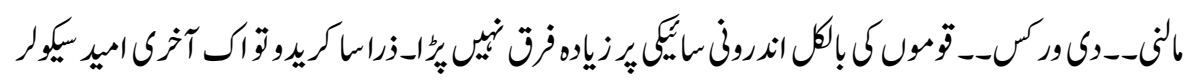

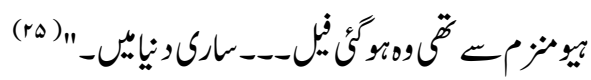

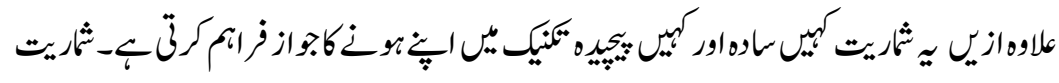

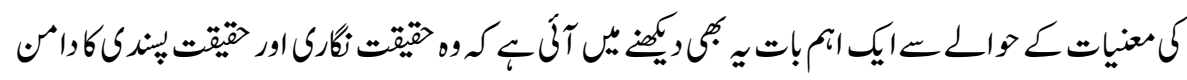

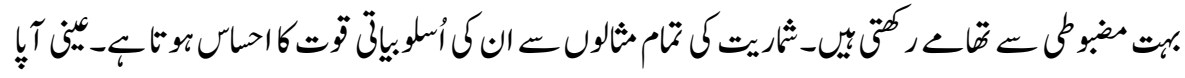

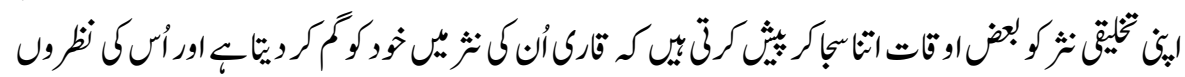

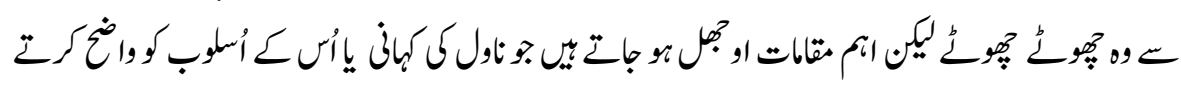

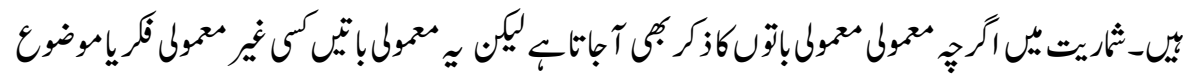




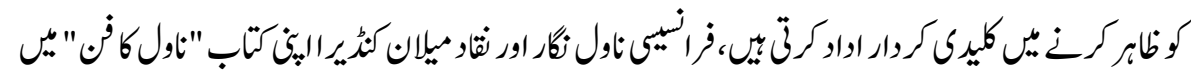
: كن

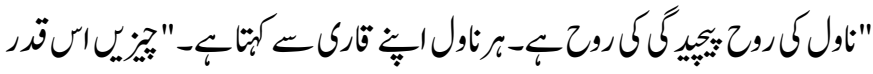

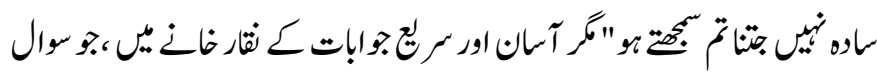

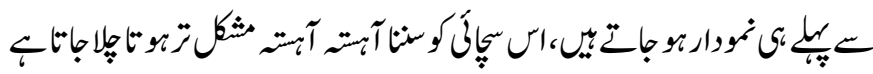

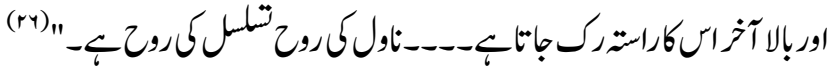

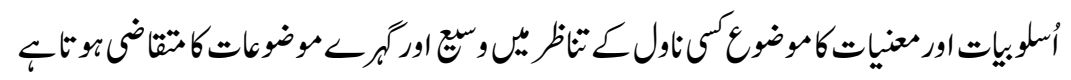

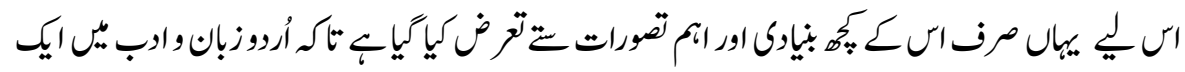

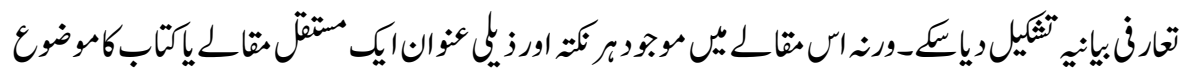
ب.

والرجات

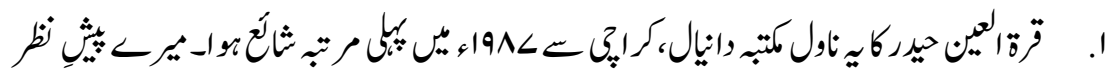

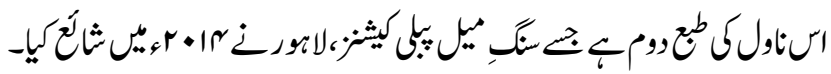

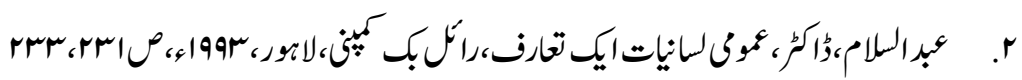

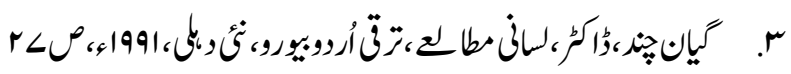

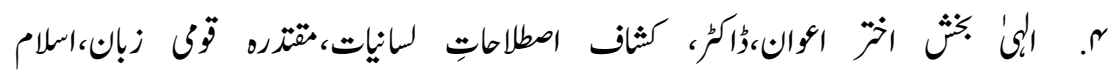

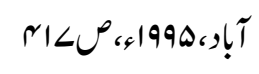

Katie Wales,A Dictionary of Stylistics,Routledge,London,2014,P ه

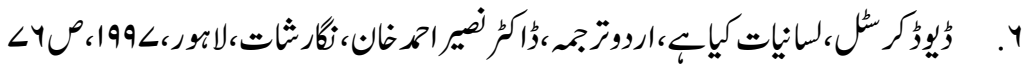




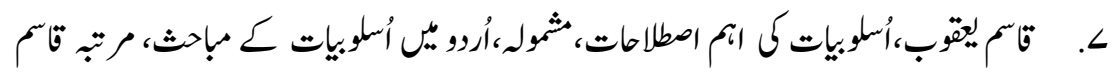

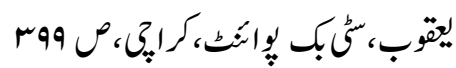

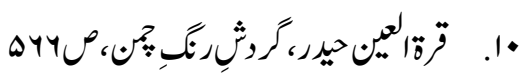

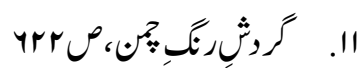

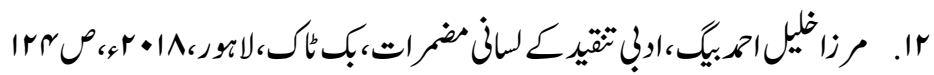

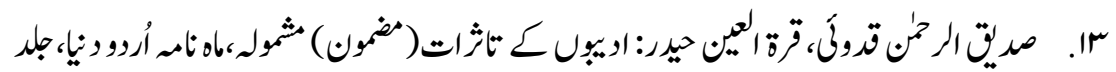

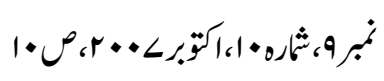

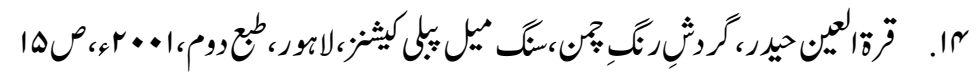

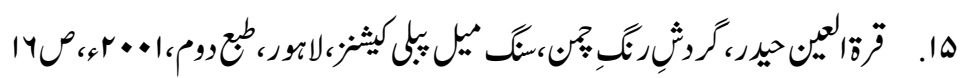

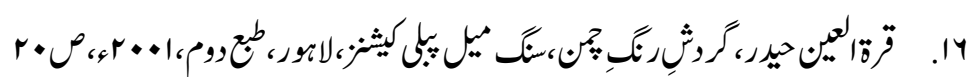

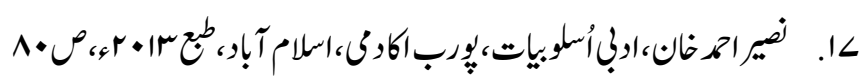

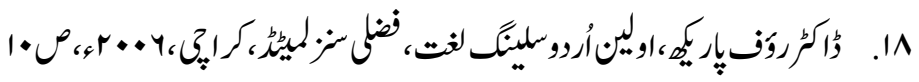

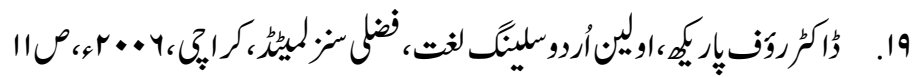

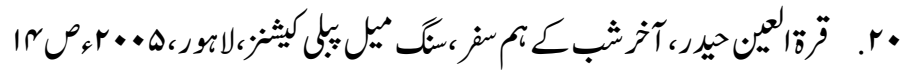

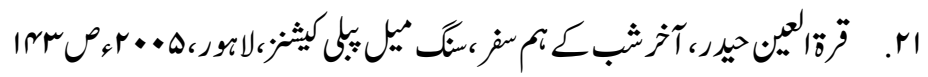

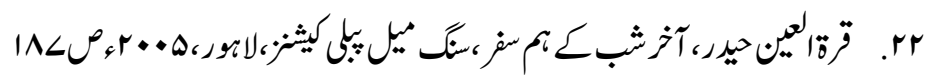

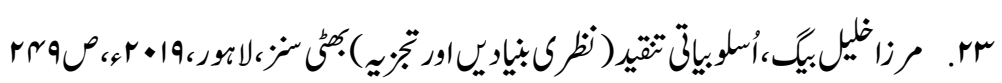

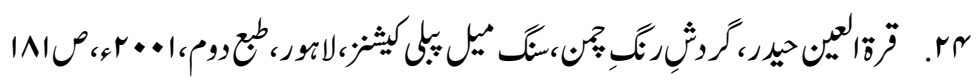




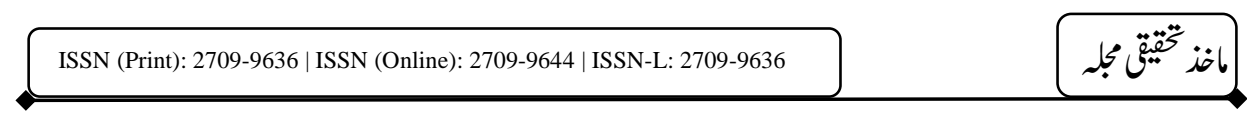

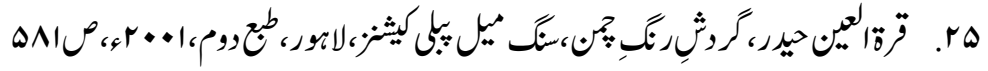

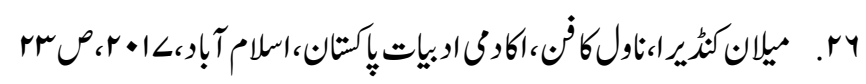

